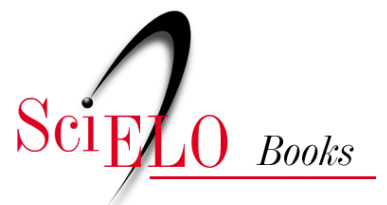

\title{
15 - A arte fotográfica: surgimento e consolidação da prática fotográfica no estado do Ceará
}

\author{
Luana Carolina da Silva Monteiro \\ Kadma Marques Rodrigues
}

\section{SciELO Books / SciELO Livros / SciELO Libros}

MONTEIRO, L. C.S., and RODRIGUES, K. M. A arte fotográfica: surgimento e consolidação da prática fotográfica no estado do Ceará. In: OLIVEIRA, G. M. C., and VIEIRA, K. M. A., eds. Patrimônio, povos do campo e memórias: diálogos com a cultura, a arte e a educação [online]. Mossoró: EdUFERSA, 2020, pp. 225-238. ISBN: 978-65-87108-09-4. https://doi.org/10.7476/9786587108605.0016.

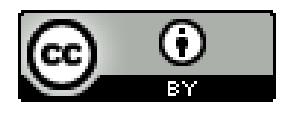

All the contents of this work, except where otherwise noted, is licensed under a Creative Commons Attribution 4.0 International license.

Todo o conteúdo deste trabalho, exceto quando houver ressalva, é publicado sob a licença Creative Commons Atribição 4.0. 


\section{A ARTE FOTOGRÁFICA: \\ SURGIMENTO E CONSOLIDAÇÃO \\ DA PRÁTICA FOTOGRÁFICA NO \\ ESTADO DO CEARÁ}

Luana Carolina da Silva Monteiro

Kadma Marques Rodrigues

\section{Introdução}

O ato de fotografar como prática social se difundiu no Estado do Ceará a partir de uma série de articulações entre diversos sujeitos sociais. Sua presença esteve relacionada por um lado ao mercado do retratismo e por outro pela massificação mercadológica da produção de imagens, com as carte de visite ${ }^{63}$. Uma disputa travada desde os seus primeiros dias no campo fotográfico e presente ainda nos dias de hoje, entre mercado e arte.

As relações estabelecidas para o desenvolvimento do campo fotográfico cearense decorreram de entrelaçamentos entre indivíduos e instituições, onde é possível notar o compartilhamento de práticas e conhecimentos, sobretudo em culturas globalizadas, que proporcionam o contato de diferentes grupos sociais. Desse modo, o desenvolvimento local da Fotografia fundamenta-se em interações que se deram antes do alvorecer do campo no Estado e que contribuíram de alguma forma para a efetivação desse processo. Para compreendê-la partimos de histórias, personagens e fatos cruciais para o desenvolvimento da fotografia como prática profissional no Estado, desdobrando-a também em suas convergências com o universo artístico.

63 Imagens fotográficas afixadas em cartões de papel de tamanho 9,5 × 6 . O cartão de visita era um presente. Sua veiculação pelos serviços de entrega postal causou um grande fluxo de trocas de carta no Brasil (ALVES, 2009). 
A defesa da arte fotográfica buscava combater diretamente a ideia de que a fotografia fosse um simples meio de reprodutibilidade do visível. O meio artístico foi uma das possibilidades de absorção e divulgação dessas produções. Juntamente com o jornalismo, a ciência e a publicidade, a arte acabou se tornando um dos pontos nodais do desenvolvimento da Fotografia no país.

Nesse sentido, no final do século XIX, o país presenciou ações que buscaram o entrelaçamento entre essas duas práticas. Os dois principais movimentos foram: os Foto Clubes ${ }^{64}$ e As semanas Nacionais da Fotografia. Ambas se configuraram em contextos de muita relevância para a difusão do ato de fotografar, possibilitando também as trocas e diálogos entre os diferentes praticantes da fotografia.

As Semanas Nacionais da Fotografia foram o desdobramento das atividades realizadas pelo Núcleo de Fotografia da Funarte, que teve seu início em $19799^{65}$. Suas ações eram de âmbito local e regional. Tinham como propósito disseminar nacionalmente a produção de vários fotógrafos ainda desconhecidos e que se encontravam espalhados em diferentes Estados do país. É dessa forma que pessoas dos diferentes Estados começam a se engajar na fotografia como a arte realizada por meio da "reprodutibilidade técnica".

\section{Fortaleza, a imagem e semelhança da civilização cearense}

No Ceará, a presença da fotografia deu-se em fins do século XIX. Em virtude dos primeiros processos de modernização, a capital, Fortaleza, conheceu a fotografia e outras inovações técnicas. Foi na Belle Époque, ${ }^{66}$ últimas décadas

64 Era uma cópia da prática francesa. O foco principal era defender o caráter artístico da Fotografia. Era composto por pessoas da classe média alta que em sua maioria estavam associadas ao movimento modernista, pessoas que se dedicavam a outras profissões que não a de fotógrafo, mas apresentavam comum interesse pela prática da fotografia (VELOSO, 2013).

65 Disponível em: www.funarte.gov.br/brasilmemoriadasartes/acervo/infoto/a-funarte-e-a-fotografia. Acesso em: 14 set. 2020.

66 Momento de modernização e urbanização da capital do Estado do Ceará. O termo em francês faz alusão ao desenvolvimento industrial e urbano presenciado na França e revela a inspiração do Estado ao se espelhar no então centro difusor 
do século XIX, que o Ceará começou a constar como Estado em contexto de urbanização. À época, o país achava-se dividido entre norte e sul, e somente após a repercussão da seca de 1877, coincidindo com o momento de efervescência do luxo vivido pelos fortalezenses, houve uma reordenação nos discursos de poder (BARBALHO, 2005).

Ary Leite (1995), com base em notícias do jornal do governo do Estado, "A República" (1892-1912), aponta fatos relacionados aos fotógrafos que habitavam a capital e àqueles que visitavam os estados divulgando seu trabalho. A chegada dos primeiros fotógrafos data de 1873, com os “[...] profissionais de fotografia Francisco Sabino Lopes Brandão, instalado à rua Palmeira, e Reckel \& Companhia, com estúdio na rua do cajueiro [...] atuais rua Major Facundo [...] e Pedro Borges" (LEITE, 1995, p. 67). Na década de 1880 outros profissionais tiveram seus nomes citados na publicidade, o Dinamarquês Niels Olsen, “[...] tem seu ateliê à rua Formosa (atual Barão do Rio Branco)"; Joaquim Antônio Corrêa, que também possuía ateliê à rua Formosa; A.A. Leão e Cia., com ateliê na Senador Pompeu (LEITE, 1995). Havia não só aqueles que se instalaram na cidade, mas os profissionais que ficavam na capital por temporada. Ambos eram responsáveis pela difusão de novidades técnicas que estavam despontando na Europa e América do Norte. Tal fato pode ser notado em 1899, no jornal "A República" quando uma nova câmera foi importada por Moura Quineau, fotógrafo sempre citado com bastante prestígio e reconhecimento na produção fotográfica do Ceará.

O hábil e inteligente artista photographo, sr. Moura Quineau, que entre nós goza o mais elevado conceito e das mais vivas e espontâneas simpatias, acaba de instalar em seu conhecido ateliê à rua Formosa, nesta capital, a Câmara Negra, também chamada Câmara Universal, destinada a aumentar e reduzir por transparencia os cliches obtidos [...] Esse aparelho gigante está sendo atualmente adquirido por todos os profissionais e amadores de arte fotográfica na Europa e é o primeiro que se importa para o Brasil (A República, 1892 apud LEITE, 1995, p. 68).

cultural, a França em fins do século XIX e início do XX. 
A fotografia realizada de modo profissional, na forma de retratos, das fotos de família e de imagens da cidade, foram os tipos mais apreciados naquele momento. O processo de urbanização e modernização crescente possibilitou aos fortalezenses que presenciaram a virada do século, um efeito progressivo do crescimento das tecnologias no cotidiano da cidade.

Mesmo se tratando de um meio técnico de produção imagética, a acessibilidade não foi um aspecto que marcou a democratização das fotografias quando estas tornaram-se presença constante na cidade de Fortaleza. Ao contrário da atual percepção da fotografia como algo de fácil acesso, naquele momento a possibilidade de ser fotografado era privilégio de poucos e só mais tarde, com as câmeras portáteis, foi possível presenciar um processo de popularização. Esse aspecto contribuiu para perpetuar a diferença entre os grupos sociais, inviabilizando para pessoas comuns a possibilidade de acesso aos avanços tecnológicos. As fotografias eram realizadas em estúdios com o amparo técnico e profissional disponível à época, mas reforçava-se o seu status de um produto artístico de difícil acesso às massas, pois o seu consumo estava restrito àqueles que faziam parte de uma pequena parcela da população, majoritariamente empresários e comerciantes (GIRÃO E HONÓRIO, 2009).

Fortaleza foi também palco de associações de fotógrafos. Como dizia a notícia do jornal "A República”, era "[...] a primeira sociedade dedicada aos artistas fotógrafos [...]" que surgia. A presença de Moura Quineau mais uma vez se tornou notória. Esteve com José Irineu, também fotógrafo de destaque na cidade, à frente na fundação do "Gremio de Propaganda Photographica" (LEITE, 1995).

Mas essa não foi a única expressão coletiva de praticantes e admiradores da fotografia em Fortaleza. Na época, Ary Leite (1995) conta que houve também na cidade várias exposições de fotografias. Muitas delas aconteceram na própria casa de Quineau. Em 1897 surgiu uma nova associação, “A Sociedade Cearense de Amadores Photographos". Em 1899, foi fundado o Photo Club Cearense ${ }^{67}$. Foi um período de bastante efervescência para os

67 Ambos movimentos pouco documentados. A principal fonte é o trabalho de Leite (1995) que fundamenta sua pesquisa nas publicações dos jornais da época. 
fotógrafos locais, porém as atividades do Club e das associações não tiveram maiores repercussões. A identidade de Quineu é também um mistério, pouco se sabe sobre ele nos dias de hoje (LEITE, 1995).

Figura 6-Rua Major Facundo-Hôtel de France

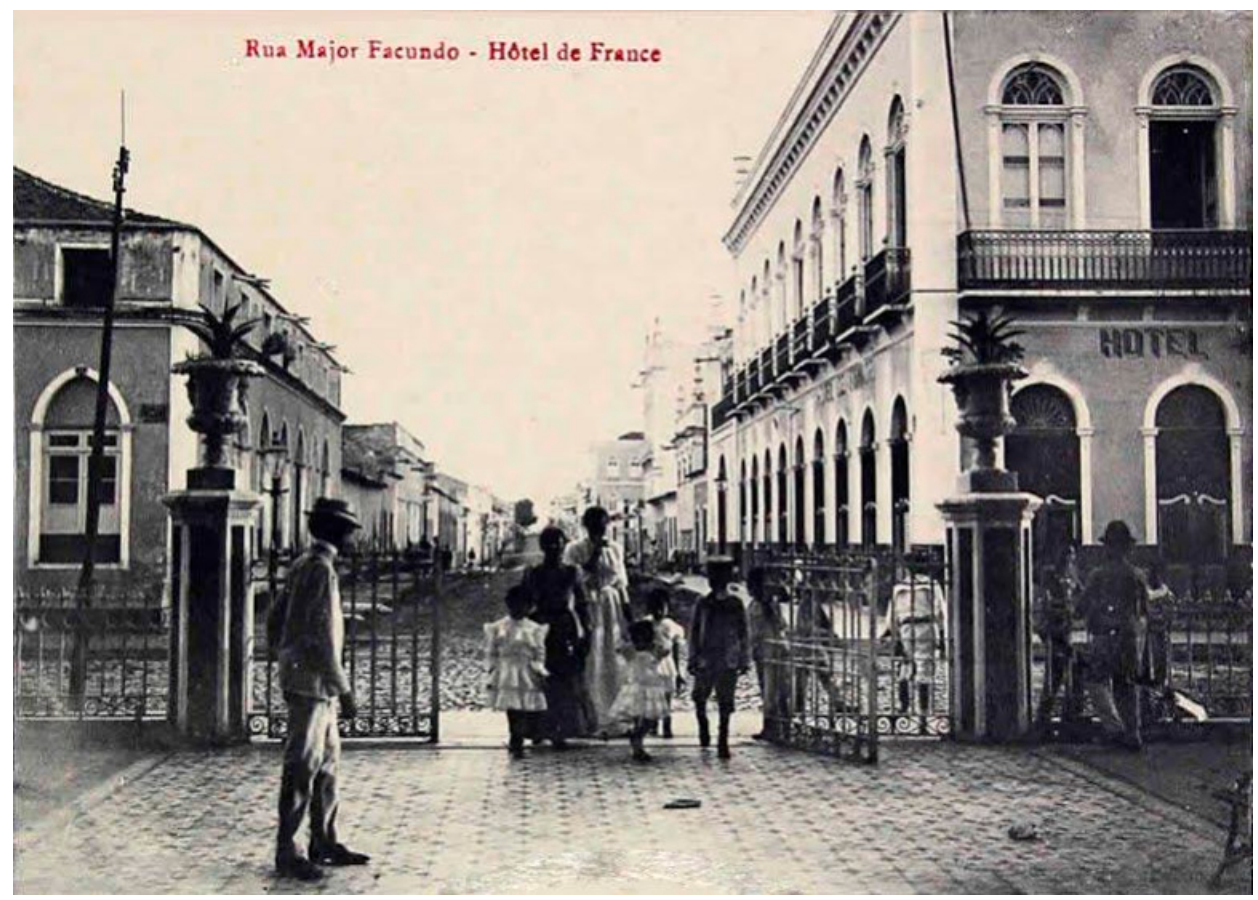

Fonte: Álbum de Vistas do Ceará (1908).

Em 1908 foi publicado o "Álbum de Vistas do Ceará”. O material foi amplamente divulgado por toda a cidade. Sem identificação dos fotógrafos na obra, o material foi composto por 160 imagens fotográficas que representavam espaços públicos urbanizados da cidade (GIRÃO E HONÓRIO, 2009). Com o intuito de imprimir local e nacionalmente uma imagem civilizada da cidade, "As vistas do Ceará" era resultado do interesse de apresentar Fortaleza e suas virtude para o mundo. Arquitetonicamente inspirada nos moldes europeus, Fortaleza estava retratada naquelas imagens como uma cidade moderna, planejada, asseada e que possuía uma elite de bom gosto. As fotografias revelam também o desejo dos representantes públicos e das elites da época pelo avanço técnico e científico. 


\section{A Belle époque e o sertão retirante}

Causa estranhamento pensar que as fotografias nesse período estavam restritas ao retratismo e à representação das modernizações da cidade, quando de 1877 a 1880 o Estado do Ceará foi palco de uma das maiores catástrofes vivenciadas no país, a estiagem de 1877.

Alguns elementos podem ser elucidados para compreender a questão: a fotografia do final do século tinha seus referenciais muito pautados na tradição pictórica, com uma clara busca pelo reconhecimento em um campo de representação imagética já estabelecido. Por esse motivo, os ensaios eram realizados no interior de estúdios e tinham predominantemente como repertório os "retratos, paisagens e naturezas-mortas" (MAYA, 2008, p. 108).

Os passos mais transformadores dessa perspectiva vieram com o estilo documental com a produção de imagens com o intuito de criar evidências para os fatos cotidianos. Para além do estúdio, outras paisagens passaram a ser percebidas pelos fotógrafos como possíveis motivos a serem registrados. Por seu turno, as imagens produzidas contribuíram para a atribuição de novos significados ao que era registrado. Outros usos puderam ser feitos da imagem fotográfica. "O valor de documentário da fotografia serviu [...] como fonte iconográfica para os estudos históricos das manifestações ocorridas fora do estúdio" (MAYA, 2008, p. 116).

A fotografia passou a ser vista com outro olhar, que expandia fronteiras. Esse foi o caminho que fez com que a fotografia se tornasse também meio de denúncia. Becker (2009) expõe a experiência vivenciada nos EUA nesse contexto de mudança do caráter da fotografia.

A "fotografia documental" era um tipo de atividade na virada do século $\mathrm{XX}$, quando grandes ondas de reforma social varreram os Estados Unidos, e os fotógrafos tinham um público fácil para imagens que expunham males e uma profusão de patrocinadores que pagavam para que eles criassem essas imagens (BECKER, 2009, p. 233).

O autor mostra o início da história de um gênero específico da fotografia, a foto como documento, como narrativa de um episódio e como testemunho. A fotografia documental, por possuir essa trajetória, reforça a perspectiva que a define como um espelho da realidade. Vê-se nela um 
caráter de infalibilidade no que concerne ao seu poder de representação do real, pois erroneamente ela é definida por, “[...] [uma] capacidade mimética [...] [que] procede[ria] de sua própria natureza técnica, de seu procedimento mecânico que permite fazer aparecer uma imagem de maneira "automática", “objetiva”, quase "natural” (DUBOIS, 2012, p. 27). Uma perspectiva que, ao privilegiar os fenômenos aparentes, deixa de lado seus aspectos imanentes.

Posteriormente a fotografia também passou a fazer parte de jornais e revistas. "[...] Considerada registro visual da realidade, passou a ser multiplicada pela reprodução gráfica, tornando-se portadora de notícia e de informação, incorporando-se como suporte da imprensa escrita" (MAYA, 2008, p. 116).

É nesse contexto que as imagens da seca de 1877 foram incorporadas aos jornais da época, criando um apelo visual e um novo tipo de testemunho. A partir da representação imagética passa a ser formulado uma representação do que seria o Sertão. As imagens da seca de 1877 chegaram até o público gerando grande repercussão. Era impensável que uma fotografia não informasse a verdade. Foi um forte impacto e a partir de então, de modo definitivo os registros fotográficos passaram a compor os jornais e os noticiários, reforçando a ideia de que uma imagem teria o potencial de expressão da "verdade" maior que o das palavras.

Os discursos produzidos com base nos relatos e imagens do Ceará em 1877 sobre a seca não deixaram de estar presentes no imaginário nacional. A partir da tragédia vivenciada no Ceará, o Nordeste passou a ser construído discursivamente como uma região-problema (ALVES, 2009). A seca se tornou fator decisivo na formação dos sertanejos. Ela foi cunhada como uma mácula na história dos sujeitos do campo.

Em 1877, milhares de flagelados, sem possibilidade de manterem-se nas suas cidades de origem, saíam em fuga. O número de mortos durante toda a seca foi contabilizado em quase meio milhão de pessoas. $\mathrm{Na}$ época, esse número representava aproximadamente $4 \%$ da população nacional (ALVES, 2009):

Os últimos anos do século XIX foram marcados por uma profunda ambivalência: por um lado, o sertão nordestino foi palco de uma das mais severas estiagens registradas na longa história social das secas 
[...] por outro, foi objeto de uma enxurrada de imagens e signos que correspondem a um elo decisivo no processo de formação do sertão nordestino como uma unidade de significado e um monopólio de sentidos (ALVES, 2009, p. 25).

A cobertura fotográfica dos acontecimentos que envolviam os retirantes causou um boom quando incorporada às matérias difundidas pelos jornais cariocas e paulistas da época. De acordo com Alves (2009) as notícias sobre a seca começaram a se espalhar em quase todo o Império. O principal correspondente foi José do Patrocínio, jornalista carioca que escreveu durante os anos de 1878 e 1879 para o jornal "Gazeta de Notícias" e "O Besouro" sobre a seca no Ceará. As cartes de visite difundidas (figura 2), que são consideradas ainda hoje como a síntese da realidade vivenciada pelos retirantes da seca de 1877, foram feitas por Joaquim Antônio Corrêa. Em cartões postais, Corrêa expôs, em "sequências de poses", nos corpos, a verdade daquela realidade. As imagens traziam versos na lateral do cartão tornando ainda mais dramático aquele registro (BARBOSA, 2002):

Mais de dez jornais foram criados para acompanhar e divulgar o flagelo. O mais importante deles foi $O$ Retirante, que continuou sendo editado mesmo após o fim da seca de 1877/79. Editado em Fortaleza e também impresso ali, o jornal era distribuído na corte e nas principais províncias do país. Fundado por um grupo de jornalistas e intelectuais, o jornal trazia os seguintes dizeres em sua capa: O Retirante: orgam das victimas da seca (ALVES, 2009, p. 26).

O mercado editorial de Fortaleza, com os jornais e folhetins, também cresceu à época com as notícias da seca. O principal jornal foi $O$ Retirante com o primeiro número lançado em 24 de junho de $1877^{68}$ e frequência semanal. O eixo temático das publicações era o contexto social enfrentado na cidade após a migração em massa presenciada da região do semiárido para as regiões mais úmidas do Ceará e outros estados.

68 Disponível em: http://portal.ceara.pro.br/index.php?option=com_content\&view $=$ article\&id=3539\&catid=297\&ltemid=101. Acesso em: 23 de mar. de 2020. 
Figura 7-Retirantes da Seca.
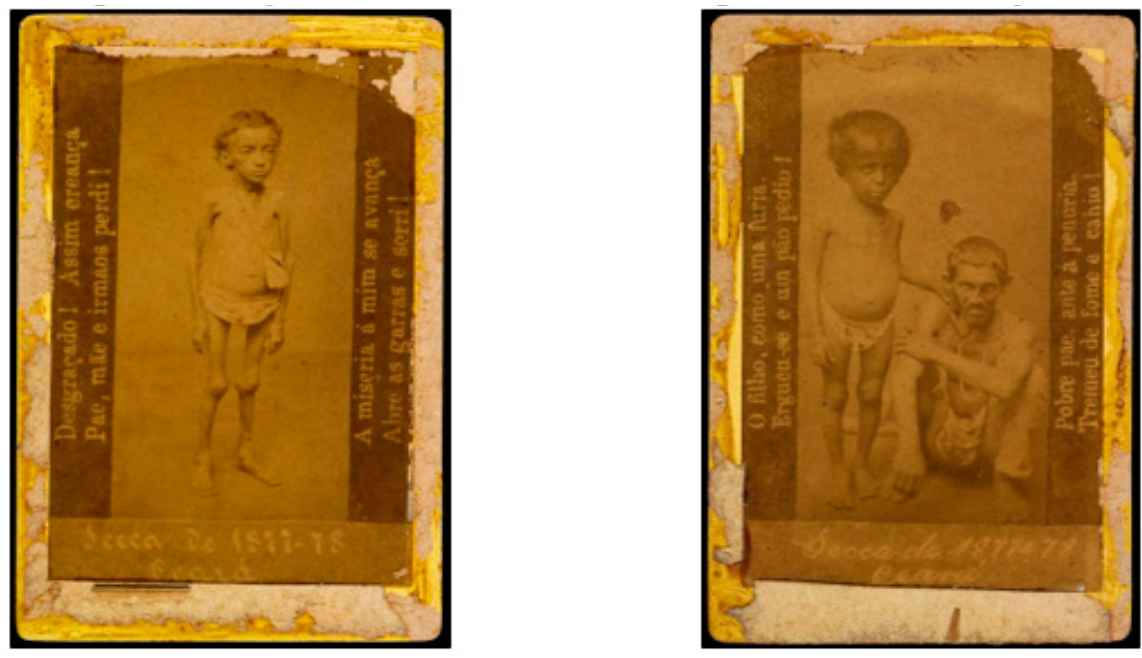

Fonte: Anais da Biblioteca Nacional, v. 114, p. 71-83, 1994.

De acordo com Alves (2009), a presença das imagens fotográficas esteve muito forte nesse como em todos os jornais que circulavam no Brasil Império. Assim, vemos, até então, duas frentes de desenvolvimento do campo fotográfico no Ceará: os fotógrafos de estúdio e os fotojornalistas.

As fotografias se impuseram como um índice de modernização [...] são vistas como um dado inconteste do avanço técnico e, portanto, da sincronização progressiva do país às realizações europeias; por outro, trazem à lume muitos aspectos políticos que não se acomodavam ao ideal antes mencionado (ALVES, 2009, p. 29).

Enquanto as imagens da alta burguesia que compunha a sociedade fortalezense eram imagens da representação de civilidade, de urbanidade e de modernização, as vítimas da seca eram associadas à animalidade. De corpos esquálidos a semblantes sofridos, tais imagens eram estampadas nos jornais e serviam principalmente para demarcar a situação abismal existente entre cidade e campo. Desenvolve-se a partir desses registros uma "Estética da Fome" (ALVES, 2009).

$\mathrm{Na}$ época, por conta das limitações técnicas das câmeras fotográficas, os retirantes precisavam ser fotografados em estúdio. A produção das imagens exigia uma longa exposição, solicitando que os "modelos" ficassem 
na mesma posição por um período de tempo. Barbalho (2005) aponta que a exposição dessas pessoas, com o uso de imobilizadores, só reforçava a dimensão desumanizadora com que eram designados socialmente.

[...] os retirantes da seca transfiguram-se em corpos que posam para o fotógrafo. Não há ali qualquer referência outra de suas vidas: de onde vieram, com que trabalhavam, qual sua família, quais os seus desejos [...] Nada. O que se vê são apenas corpos que causam repugnância (e ao mesmo tempo atraem) em seu estado de dilaceramento (BARBALHO, 2005, p. 07).

A seca é ainda uma memória muitas vezes acessada para reforçar as diferenças existentes entre campo e cidade. Mas, para além de uma mácula na história do Ceará é uma memória social produtora de novos contextos. Tanto a seca como um problema social passou a ser nacionalmente abordada, quanto a vida dos milhares de nordestinos esquecidos pelas políticas públicas passaram a ser contabilizadas. $O$ país que antes era dividido entre norte e sul, recebeu a delimitação "nordeste".

\section{Considerações Finais}

Desse modo, é possível afirmar que o início da Fotografia no Estado do Ceará esteve vinculado a dois momentos emblemáticos na nossa história: a Belle Époque como o período de ascensão do Estado e do desenvolvimento arquitetural e urbanístico e a estiagem de 1877 e a migração em massa dos retirantes do interior do Estado para a capital. A imagem fotográfica aparece nessa época como legítima representante do espaço de modernização da estrutura e das relações sociais na urbe; e o registro da seca de 1877-79, surge nas páginas dos jornais como um retrato do atraso. E esse atraso tem o importante papel de reforçar os dualismos vivenciados entre campo e cidade. Como Alves (2009) aponta, as imagens da seca serviram principalmente para a formação social, geográfica e cultural de um lugar chamado Nordeste. Assim, mais uma vez se viu reforçada a distância entre cidade e campo; um, como o epicentro do desenvolvimento humano e o outro, como o lugar em que os indivíduos ainda se encontravam presos à sua natureza. 
Muitos são os elementos constitutivos do imaginário de Sertão que foram socialmente atribuídos com o passar do tempo e ganharam uma projeção nacional. Entre eles a seca é somente o primeiro. Por possuírem uma repercussão nacional de grande proporção, são também formadoras de uma identidade local, como afirma Alves (2009). A fotografia, em sua vertente documental, por seu histórico com o contexto de denúncia, passa a ser reduzida à prova e documento. E o campo artístico, mesmo ao se ver transpassado pelo avanço da técnica e da industrialização das formas com a fotografia não se tornou uma contenção para o seu desenvolvimento. Ao longo dos anos a fotografia passou a ser reconhecida em seu próprio campo, recebendo também reconhecimento no Estado; um trajeto longo que culminou em diferentes movimentos dos grupos de fotógrafos como eventos, cursos, exposições e a criação de um Museu da Fotografia de Fortaleza $(\mathrm{MFF})^{69}$.

69 É uma instituição de arte com um acervo de mais de duas mil imagens fotográficas de diferentes fotógrafos brasileiros e estrangeiros. Sua fundação foi feita com o intuito de receber o acervo das obras dos colecionistas Paula e Silvio Frota. 


\section{REFERÊNCIAS}

\section{ALVES, E. P. M. A Economia simbólica da cultura popular}

sertanejo-nordestina. 2009. Tese (Doutorado em Sociologia) Universidade de Brasília, Brasília, 2009.

BARBALHO, A. Corpos e mentes dilacerados: o grotesco nas imagens da seca de 1877. Trajetos Revista de História UFC, v. 3, n. 6, p. 139-150, 2005. Disponível em: http://www.repositorio.ufc.br/handle/ riufc/19985. Acesso em: 20 jun. 2017.

BARBOSA, M. E. J. Imprensa e fotografia: imagens de pobreza no Ceará entre o final do século XIX e início do século XX. São Paulo: Projeto História, 2002.

BECKER, H. S. Sociologia visual, fotografia documental e fotojornalismo. In:

BECKER, H. S. Falando da sociedade: ensaio sobre as diferentes maneiras de representar o social. Rio de Janeiro: Jorge Zahar, 2009. GIRÃO, I.; HONÓRIO, E. A Fotografia e a imagem em movimento em Fortaleza no final do século XIX e início do século XX. In: ENCONTRO NACIONAL DE HISTÓRIA DA MÍDIA, MÍDIA ALTERNATIVA E ALTERNATIVAS MIDIÁTICAS, 7., 2009, Fortaleza. Anais [...]. Fortaleza: 2009.

LEITE, A. B. Fortaleza e a era do cinema: pesquisa histórica (18911931). Fortaleza: Secretaria da Cultura, 1995. 
MAIA, R. S. A Paisagem na fotografia documental contemporânea: tendências estéticas na obra Paisagem Submersa. 2013. 131 f.

Dissertação (Mestrado em Comunicação) - Universidade Federal Fluminense, Niterói, 2013.

VELOSO, P. R. M. O Mundo em si: o moderno e o contemporâneo na fotografia de Chico Albuquerque e Gentil Barreira. 2013. $145 \mathrm{f}$. Dissertação (Mestrado em Comunicação Social) - Universidade Federal do Ceará, Fortaleza, 2013. 